\title{
Small RNA pathways in Schmidtea mediterranea
}

\author{
ALISSA M. RESCH ${ }^{1}$ and DASARADHI PALAKODETI*,2 \\ ${ }^{1}$ Department of Genetics and Developmental Biology, Stem Cell Institute, University of Connecticut Health Center, \\ Farmington, Connecticut, USA and ${ }^{2}$ Institute of Stem Cell Biology and Regenerative Medicine, Bangalore, India
}

\begin{abstract}
Planarians are bilaterally symmetrical fresh water organisms capable of regenerating body parts from small fragments following bodily injury. Planarians possess a specialized population of pluripotent cells called neoblasts, which are responsible for their unique regenerative ability. The study of planarian stem cell biology and regeneration has traditionally focused on the transcription factors and proteins that regulate signal transduction pathways. New evidence shows that small RNA molecules are important players in stem cell function and regeneration, yet little is known about the exact nature of their regulatory roles during the regenerative process. In this review, we discuss biogenesis of microRNAs and piwiRNAs and their functional role in key developmental pathways in vertebrates and invertebrates with an emphasis on recent studies on planarian small RNA pathways.
\end{abstract}

KEY WORDS: small RNA, piRNA, miRNA, planarian, regeneration

\section{Introduction}

Planarians have emerged as a robust model organism for studying regeneration and stem cell biology, because of specialized adult stem cells called neoblasts, which are pluripotent (Wagner et al., 2011 ) in nature. Neoblasts are 5-10 $\mu \mathrm{m}$ in length and constitute 25$30 \%$ of the total cell population. They are also characterized by a large nucleus and scant cytoplasm and are extremely sensitive to irradiation. The advent of molecular tools including RNAinterference, in-situ hybridization and next generation sequencing has greatly enhanced our understanding of the molecular pathways involved in regeneration and neoblast function in planarians. Several key proteins involved in various signaling pathways have been shown to play roles in planarian stem cell proliferation, differentiation and pattern formation (Adell et al., 2010; Gentile et al., 2011; Pearson and Sanchez 2010). For instance, knockdown of $\beta$-catenin-1, a major component of the Wnt signaling pathway, results in head formation on both anterior and posterior ends of the planarian, suggesting that a potential gradient of $\beta$-Catenin with increased levels of $\beta$-Catenin at the posterior end, leads to inhibition of head formation at the posterior side of the animal (Peterson and Reddien 2008; Gurley et al., 2008).

In recent years, small RNA pathways have gained prominence because of their diverse role in controlling various cellular processes such as cell cycle regulation, apoptosis and development (Thatcher and Patton 2010). Among various small RNA pathways, the microRNA pathway is well studied and regulates gene expres- sion primarily through translational repression of target mRNAs (Liu and Paroo 2010). Other small RNA molecules such as piwiRNAs (piRNAs) and endosiRNAs are mostly involved in transposon regulation, with the exception of pachytene piRNAs, whose functions are not clear. Recent studies in planarians have identified genes that encode proteins involved in small RNA biogenesis that are important for neoblast function and planarian regeneration. These studies provide indirect evidence for the involvement of small RNAs in planarian regeneration and neoblastfunction, but additional studies are needed to determine the exact roles of small non-coding RNAs in planarian stem cell function. In the present review, we focus on two classes of small RNAs, microRNAs (miRNAs) and piwiRNAs (piRNAs), and their regulatory roles in planarian stem cell function and regeneration.

\section{miRNA processing}

MicroRNAs represent an abundant class of small RNAs that repress gene expression post-transcriptionally by binding to complementary regions of 3' untranslated regions (3'UTR) and coding sequence (CDS) in target messenger RNA (mRNA) sequences. MicroRNA encoding genes are transcribed by RNA polymerase II as long primary-miRNA (pri-miRNA) transcripts (Lee et al., 2004), and in some cases, human miRNAs located within Alu repeat ele-

Abbreviations used in this paper: CDS, coding sequence; ES cells, embryonic stem cells; miRNA, microRNA; piRNA, Piwi RNA; pri-miRNA, primary-miRNA.

\footnotetext{
*Address correspondence to: Dasaradhi Palakodeti. Wellcome/DBT intermediate fellow, Institute of Stem Cell Biology and Regenerative Medicine (inStem), NCBS, GKVK campus, Bangalore-560065, India.Tel: +91-80-6718-5206. e-mail: dasaradhip@ ncbs.res.in ; palakodeti76@gmail.com
} 
ments are transcribed by RNA pollII (Borchert et al., 2006). Drosha and its partner DGCR8/PASHA process pri-miRNA transcripts into precursor miRNA (pre-miRNA). Pre-miRNA is then exported from the nucleus to the cytoplasm by Exportin 5, where it is processed into 21 nt double-stranded miRNA by Dicer and R3D1/Loquacious. The mature miRNA is loaded onto the Argonaute protein, which is part of a huge protein complex called the RNA induced silencing complex (RISC). The mature strand acts like a guide and recruits RISC to the 3'UTR of the target mRNA leading to either translational repression or mRNA degradation (Fig. 1). The mRNA bound by miRNA and RISC is processed in specialized components called $P$ bodies and stress granules, which are the functional equivalent of chromatoid bodies present in germ line tissues (Liu and Paroo 2010).

\section{miRNAs in stem cells}

MicroRNAs are emerging as key regulators of gene expression and are implicated in many biological processes including stem cell biology (Bartel 2004). MicroRNAs down-regulate large numbers of transcripts resulting in wide spread changes in protein levels in metazoans (Baek et al., 2008; Selbach et al., 2008). Dicer-1 knockout studies in mouse embryonic stem (ES) cells showed that these cells fail to differentiate upon induction, indicating a role for Dicer-dependent factors in cellular differentiation. However, this study did not establish the specific role of the miRNA pathway in ES cells because Dicer-1 in mammals is also involved in the siRNA pathway (Kanellopoulou et al., 2005). On the other hand, DGCR8 knockout ES cells specifically inhibited microRNA biogenesis, but not siRNA biogenesis. When induced, these knockout ES cells failed to down-regulate pluripotency markers and retained the capacity to form ES cell colonies. These studies established a role for microRNAs in differentiation of embryonic stem cells (Wang et al., 2007). In another study, the Lin-28 RNA binding protein was shown to be essential for maintenance of ES cells by blocking the processing of pre-let-7 by Dicer-1 (Viswanathan et al., 2008). Interestingly, most of these studies suggest that miRNAs are primarily involved in ES cell differentiation, but not maintenance. Recent studies have addressed this question. Hanina and co-authors demonstrated that miRNA cluster mir290-295 promotes pluripotency by up-regulating pluripotency associated genes such as lin-28 (Hanina et al., 2010). In an independent study, Subramanyam and co-authors demonstrated that hsa-mir302b and hsa-mir-372 miRNAs are sufficient to reprogram mouse embryonic fibroblasts to induced pluripotent stem (iPS) cells, emphasizing a key role for miRNAs in the maintenance of ES cells (Subramanyam et al., 2011). In addition, mir-335 expressed in human mesenchymal stem (MS) cells is essential for cell proliferation and is up-regulated by the canonical Wnt signaling pathway and down-regulated by interferon gamma. Western blot analysis and 3'UTR reporter assays confirmed RUNX2, a key protein for the reparative phenotype of MS cells, which involves migration and differentiation, as a direct target for mir-335. This suggests that down-regulation of mir-335 is essential for the upregulation of RUNX2, which mediates migration and differentiation of MS cells (Tomé et al., 2011). Experimental findings also show that miRNAs are involved in adult stem cell function in neural stem cells, hematopoietic stem cells, and others (Yi and Fuchs 2011). Most studies that investigate miRNA function in stem cells have been carried out in vitro, therefore it is unclear how miRNAs regulate the stem cell niche. Thus, there is great need for a tractable in vivo system for studying stem cell function and the niche that regulates stem cells. In this regard, planarians serve as an excellent in vivo model for examining the expression patterns and regulatory functions of miRNAs. Further, the study of miRNAs essential for stem cell function in invertebrate species like planarians and Hydra will enable comparative studies between invertebrates and vertebrates, and thus increase our understanding of the evolutionary aspects of miRNA function with respect to stem cell biology.

\section{Planarian miRNAs}

Planarian regeneration is facilitated by a population of specialized cells called neoblasts, which contain a dense nucleus and reduced cytoplasm compared with non-neoblast cell types. The neoblast cytoplasm is further characterized by the presence of dense cytoplasmic RNP granules called chromatoid bodies. Chromatoid
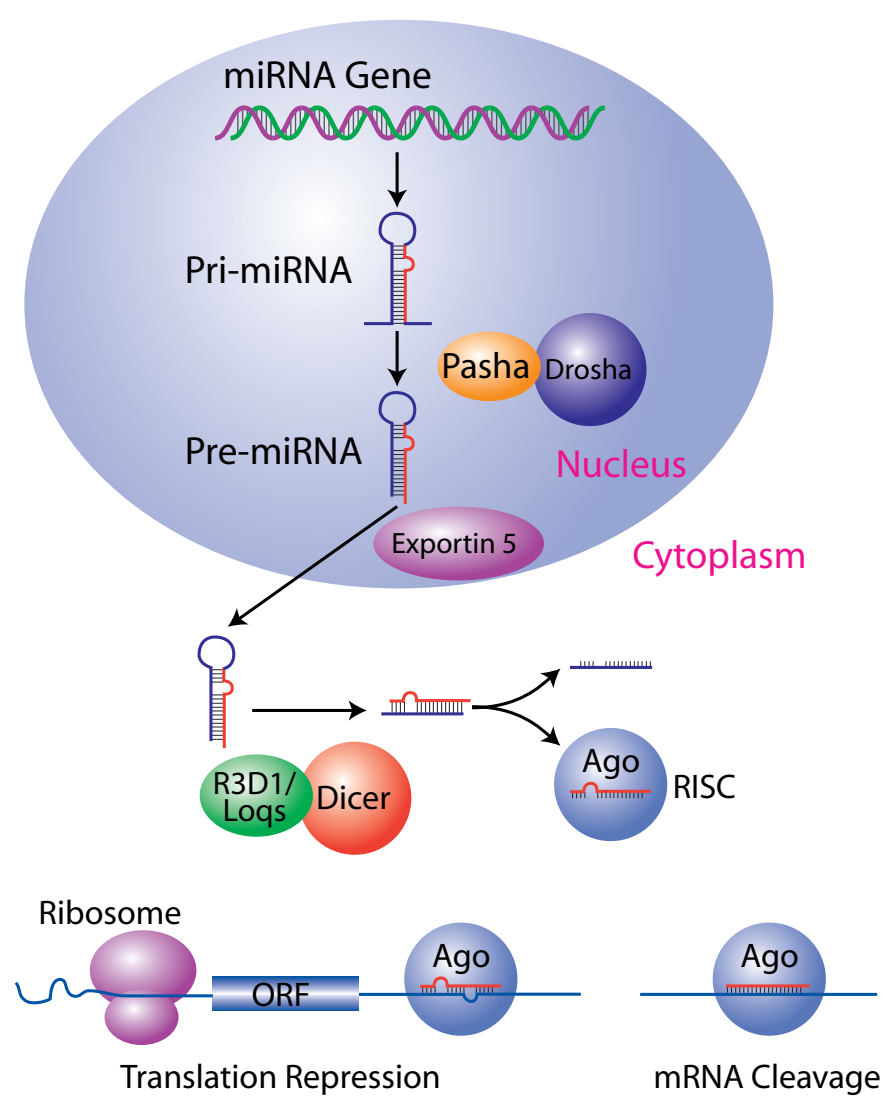

Fig. 1. MicroRNA biogenesis. MicroRNAs (miRNAs) are small RNA molecules that regulate post-transcriptional silencing of gene expression by binding to the complementary $3^{\prime} U T R$ of target mRNA. The miRNA gene is transcribed by RNA Polymerase II into primary-miRNA (pri-miRNA), which is processed by Drosha along with its partner Pasha to generate precursor-miRNA (pre-miRNA). The precursor miRNA is exported from the nucleus to the cytoplasm by Exportin 5, where it is processed by Dicer and R3D1 to generate small RNAs 21-22 nt in length. The double stranded small RNA is unwound and the mature miRNA is loaded onto Argonaute, which is part of the RNA induced silencing complex (RISC). The mature small RNA acts as a guide strand and recruits RISC to the 3'UTR of the target $m R N A$. The target $m R N A$ is either translationally repressed if the seed region of miRNA lacks perfect complementarity with the 3' UTR, or cleaved if the seed region has perfect complementarity. 
TABLE 1

\section{COMPARISON OF GENES THAT ENCODE PROTEINS ESSENTIAL FOR SMALL RNA BIOGENESIS IN THE PLANARIAN SCHMIDTEA MEDITERRANEA, DROSOPHILA MELANOGASTER, MUS MUSCULUS AND HOMO SAPIENS}

\begin{tabular}{lcccc}
$\begin{array}{l}\text { Proteins involved } \\
\text { in small RNA biogénesis }\end{array}$ & S. mediterranea & D. melanogaster & M.musculus & H. sapien \\
\hline microRNA and siRNA pathway & & & & \\
Drosha & + & + & + & + \\
Pasha (DGCR8) & + & + & + & + \\
Dicer & DICER1 & DICER1 & + & + \\
& DICER2 & DICER2 & & \\
R3D1 (Loquacious/TRBP2) & + & + & + & + \\
R2D2 & - & + & + & + \\
Argonaute & AGO1 & AGO1 & AGO1 & AGO1 \\
& AGO2 & AGO2 & AGO2 & AGO2 \\
& & & AGO3 & AGO3 \\
& & & AGO4 & \\
& & & AGO5 & \\
piRNA pathway & & & & \\
Piwi & & & MILI & HILI \\
& SMEDWI-1 & AGO3 & MIWI & HIWI1 \\
& SMEDWI-2 & AUB & MIWI2 & HIWI2 \\
& SMEDWI-3 & PIWI & MIWI & HIWI3 \\
\hline
\end{tabular}

The accession numbers for Mus musculus (mouse), Homo sapiens (human), Drosophila melanogaster (fly) and Schmidtea mediterranea (planarian) proteins are as follows: Mouse (Mmu): DICER1 (AAH61198), DROSHA (NP_001123621), DGCR8 (NP_201581), TRBP2 (NP_033345), AGO1 (NP_700452), AGO2 (NP_694818), AGO3 (NP_700451), AGO4 (NP 694817), AGO5 (AN75582); Human (Hs): DROSHA (NP 037367), DGCR8 (NP 073557), DICER1 (NP 001182502), TRBP2 (NP_004169), AGO1 (NP_036331), AGO2 (NP_036286), AGO3 (NP_079128), AGO4 (NP_060099), HILI (NP_060538), HIWI (NP_004755) HIWI2 (NP_689644), HIWI3 (NP_001008496); Drosophila (Dm): DROSHA(NP 477436), PASHA(NP 651879), DICER1 (NP 524453), DICER2 (NP 523778), R3D1 (NP_001188796), AGO1 (NP_725341), AGO2 (NP_730054), AGO3 (ABO27430), Aubergine (CAA64320), PIWI (NP_476875); Planarian (Sme):SMEDWI-1 (Q2Q5Y9), SMEDWI-2 (ABB77338), SMEDWI-3 (ACC97187), AGO2 (ADY05336.1).

bodies in mammals are associated with germ cells and exist as huge RNA-protein complexes that include small RNAs and RNA binding proteins essential for translational repression and small RNA biogenesis (Kotaja et al., 2007). Recent studies in planarians identified several genes that encode RNA binding proteins such as TIA-1, LSm, elF-4A, elF-4G, TRDR-1, SMN, CBC-1, TUD-1, PIWI, DICER-1, FMRP-1 and Ago-2. These genes are expressed in neoblasts and some of them were shown to be essential for neoblast function and regeneration (Rouhana et al., 2010). In C. elegans, Drosophila and mammals, most of these proteins are associated with various RNP granules such as P-bodies, stress granules and chromatoid bodies (Kotaja et al., 2007). In contrast, the cellular localization of most of these RNA binding proteins expressed in planarian neoblasts is unknown. Three recent reports showed that the planarian proteins DjCBC-1 (Yoshida-Kashikawa et al., 2007), Smed-SmB (Fernandez-Taboada et al., 2010) and SPOLTUD-1 (Solano et al., 2009) are localized to chromatoid bodies, raising the possibility that other neoblast enriched RNA binding proteins may exhibit similar patterns of localization. The study of RNA binding protein localization patterns in neoblasts will provide valuable insight about the types of RNAmolecules that localize to chromatoid bodies and thus the function of chromatoid bodies in neoblast cells.

Many of the genes that encode proteins essential for small RNA biogenesis in other animal species have recently been identified in the planarian Schmidtea mediterranea (Table 1)(Reddien et al., 2004; Palakodeti et al., 2008; Li et al., 2011). Knock downs of some of these genes led to defects in regeneration, suggesting that planarian small RNAs are important for regeneration and neoblast function. For example, knock down of ago-2 expression by RNAi in the planarians Dugesia japonia (Rouhana et al., 2010) and Schmidtea mediterranea (Li et al., 2011) resulted in defects in regeneration and the loss of neoblast cell populations. It is not clear whether the observed defects in regeneration are due to loss of miRNA function, since ago-2 knockdowns could lead to loss of both miRNAs and endogenous siRNAs. Knocking down either DGCR8 or Drosha, both of which are involved in miRNAbiogenesis, will be helpful in establishing the exact nature of miRNA function in the regeneration process. Several microRNAs were recently identified in Schmidtea mediterranea; many of these are highly conserved across the animal kingdom and a few are planarian specific (Palakodeti et al., 2006; Lu et al., 2009; Friedländer et al., 2009). In addition, many miRNA clusters were identified in Schmidtea mediterranea. Of these, the mir-71 and mir-2 clusters are conserved in Schistosoma, a parasitic worm that belongs to the phylum Platyhelminthes, which also includes Schmidtea (Huang et al., 2009; Simões et al., 2011). These observations suggest that evolutionarily conserved clusters might share similar functions and similar modes of regulation. It was recently shown that planarian miRNAs are expressed in strain-specific and neoblast-specific fashion. Deep sequencing of small RNA libraries from irradiated and non-irradiated sexual and asexual strains and adult neoblast cell populations from Schmidtea mediterranea revealed numerous examples of strain-specific and neoblast-specific miRNA expression (Lu et al., 2009; Friedländer et al., 2009).

\section{Strain specific miRNAs}

Schmidtea mediterranea exist in nature as sexual and asexual strains. Sexual strains are hermaphroditic with mature testis and ovaries. In contrast, asexual strains lack mature germ line tissue, but still contain nanos mRNA expressing cells with a distribution similar to that of presumptive testes primordia in the sexual worm (Wang et al., 2007). Further, asexual strains undergo asexual reproduction by fission, which is not observed in sexual strains. Karyotyping experiments performed on both strains revealed a chromosomal translocation in asexual animals, which might explain the absence of well-developed germ line tissues and the ability of the asexual strain to reproduce through fission (Newmark and Sanchez 2002). Identifying differences in gene expression between sexual and asexual strains will help to identify factors involved in germ line development and fission. Deep sequencing of small RNA libraries from sexual and asexual strains revealed several cases of strain-specific miRNA expression. Interestingly, the majority of asexual specific miRNAs are planarian specific, except for mir-76, which has been identified in other species (Lu et al., 2009). This raises the possibility that miRNAs enriched in the asexual strain may have evolved independently in planarians; it is unclear whether asexual-specific miRNA expression is linked to the chromosomal translocation, but it may contribute to the reproductive mode of asexuals and their inability to form germ line tissues. In contrast, sexual-specific miRNAs might be involved in sexual reproduction and the development of germline tissue.

\section{Neoblast specific miRNAs}

The regeneration process in planarians starts with wound healing mediated by the migration of epidermis adjacent to the wound region (Pascolini etal., 1984). Later steps involve neoblastmigration to the site 
of injury followed by rapid proliferation and differentiation into variouscell types and tissues (Handberg-Thorsager etal., 2008). Deep sequencing of small RNA libraries from non-irradiated and irradiated animals and neoblast cells identified several miRNAs that were irradiation-sensitive and expressed in the neoblast cell population. In planarians, let-7a miRNA expression showed a marked decrease upon irradiation (Lu et al., 2009, Friedländer et al., 2009). In contrast, let-7a expression in mammals is suppressed in mammalian embryonic stem (ES) cells and expressed upon differentiation. Interestingly, lin-28, a suppressor of pre-let-7a processing, was expressed in mammalian ES cells, whereas in planarians lin-28 was expressed in differentiated tissues, indicating a reversal in function and expression for let-7a and lin-28 during evolution. Deep sequencing of small RNAlibraries also revealed that miRNAs belonging to the major miRNA cluster mir71a/2d/13/752 were sensitive to irradiation and expressed in the neoblast population, suggesting that miRNAs belonging to the same cluster may be co-regulated (Lu et al., 2009, Friedländer et al., 2009). Nonetheless, it is important to consider the expression of individual miRNAs from the same cluster within different neoblast populations (i.e. proliferating neoblasts and neoblast progeny) in order to understand how individual miRNAs from the same cluster are processed. Whole mount in-situ hybridization of 41 miRNAs revealed that the majority of miRNAs in this cluster are expressed in the central nervous system and in mesenchymal tissue where the neoblast resides (González-Estévez et al., 2009). In this study, probes were designed to identify the expression pattern of pri-miRNA rather than the mature miRNA, which might not reflect the actual expression pattern of mature miRNA. For instance, mammalian pre-let-7miRNA is expressed in ES cells, whereas mature let-7is present in differentiated cells. Diverse patterns of expression for several pri-miRNAs were also observed along the anterior posterior axis, indicating a potential role for miRNAs in maintaining AP polarity (González-Estévez et al., 2009). Zebrafish mir-133, which is also conserved in planarians, was recently shown to be down-regulated during fin regeneration. Wnt and Fgf appear to be major targets of zebrafish mir-133 and these genes are essential for wound healing, neoblast proliferation and AP polarity in planarians (Thatcher and Patton 2010). Furthermore, González-Estévez et al., showed that pri-miRNAs are expressed in cephalic ganglion, a complex network of neurons in the central nervous system (CNS) (González-Estévez etal., 2009). Planarians exhibit continuous remodeling of their bodies, which is prominent in the CNS and requires precise regulation of synaptic development. Planarian miRNAs are likely to play an important role in CNS development, but additional studies are required to determine the mechanism by which CNS-specific miRNAs regulate regeneration and neural wiring. Another area of interest is to identify the targets of miRNAs that are expressed during CNS regeneration; this will enhance our understanding of the specific regulatory roles that miRNAs play during neural development and regeneration.

\section{Piwi RNA biogenesis}

Piwi RNAs (piRNAs) are a relatively new class of small RNA molecules that range from 24-32 nt in length. Cloning studies in Drosophila identified small RNAs that mapped primarily to transposable elements and were called repeat associated small RNAs (rasiRNAs) (Aravin et al., 2003). Later studies revealed that these small RNAs were processed by a Dicer independent pathway and associated with one of the Argonaute class of proteins called PIWI's, hence the name piwiRNAs or piRNAs (Vagin et al., 2006).
Piwi proteins are identified by the presence of two domains: a PAZ (Piwi/Argonaute/Zwille) domain that interacts with 3'end of the small RNA and a Piwi domain that carries out endonuclease activity (Hutvagner et al., 2008). These proteins are primarily expressed in the germ line tissues of vertebrates and invertebrates. Knockdown of PIWI's in Drosophila and mice led to failure in oogenesis and spermatogenesis (Thomson and Lin 2009). In Drosophila, there are three different Piwi proteins:AGO3, Aubergine (AUB) and PIWI, which are mostly expressed in the ovaries. Aubergine and AGO3 expression is restricted to germline stem cells, whereas PIWI is expressed in germline stem cells and somatic follicular cells. Cross linked immuno-precipitation using antibodies against different Piwi proteins in Drosophila, followed by deep sequencing of small RNAs associated with Piwis, revealed that different Piwi proteins interact with different sizes of small RNAs that range in length from 24-30nt. Most piRNAs that associate with different Drosophila Piwi proteins map to specific loci near centromeric regions enriched with transposable elements. The same study showed that Piwi proteins exhibit strand specificity in their interactions with piRNAs. For example, AGO3 interacts with the sense strand while PIWI and AUB interact with the antisense strand. It was also shown that sense piRNAs associated with AGO3 and antisense associated with AUB show partial complementarity of $10 \mathrm{nts}$ at their 5 ' ends. These observations form the basis of the ping-pong model that describes piRNA biogenesis in Drosophila. According to the ping-pong model, a long precursor RNA is transcribed from the master loci, which is antisense to transposable elements enriched at the loci. Sense piRNAs bound by AGO3 base pairs with the precursor RNA, and then $\mathrm{AGO} 3$ cleaves the precursor to generate antisense piRNAs. AGO3 processed antisense piRNAs share partial complementarity with the sense piRNAs. The antisense piRNA generated from the precursor RNA binds to AUB and base pairs with active transposable elements to generate secondary sense piRNAs, which in turn bind to AGO3 and generate antisense piRNAs, resulting in a feed forward loop amplification of piRNA (Brennecke et al., 2007) (Fig. 2A). A ping-pong independent pathway was also identified in Drosophila, and is mediated by Piwi proteins bound to antisense piRNAs (Fig. 2B). The ping-pong pathway appears to be prevalent in germline stem cells (GSC), while the ping-pong independent pathway is mostly observed in somatic follicular cells, which is consistent with expression patterns for AUB, AGO3 and PIWI (Malone et al., 2009; Li et al., 2009).

In contrast to Drosophila, mouse piRNAs are mostly expressed in the testis and are important in spermatogenesis. The mouse Piwi proteins, MIWI, MIWI-2 and MILI are expressed during different stages of spermatogenesis. MIWI is expressed from the meiotic-1 pachytene stage to the elongated spermatid stage, where MIWI-2 expression occurs during early spermatogenesis. Interestingly, MILI expression overlaps with both MIWI-2 and MIWI, and is detected from early spermatogenesis until the formation of round spermatids. Knock down of mili and miwi-2 results in spermatogenic stem cell arrest during early spermatogenesis in pre-natal mice. In addition, miwi-2 deficient mice showed rapid degeneration of spermatogonia, suggesting a possible role for MIWI-2 in the maintenance of germline stem cells. Miwi deficient mice result in male sterility, which is characterized by the inhibition of spermatogenesis at the early spermatid stage (Thomson and Lin 2009). Deep sequencing of small RNAs in mouse revealed two different classes of piRNAs. The first class of mouse piRNAs are called pre-pachytene piRNAs 
A

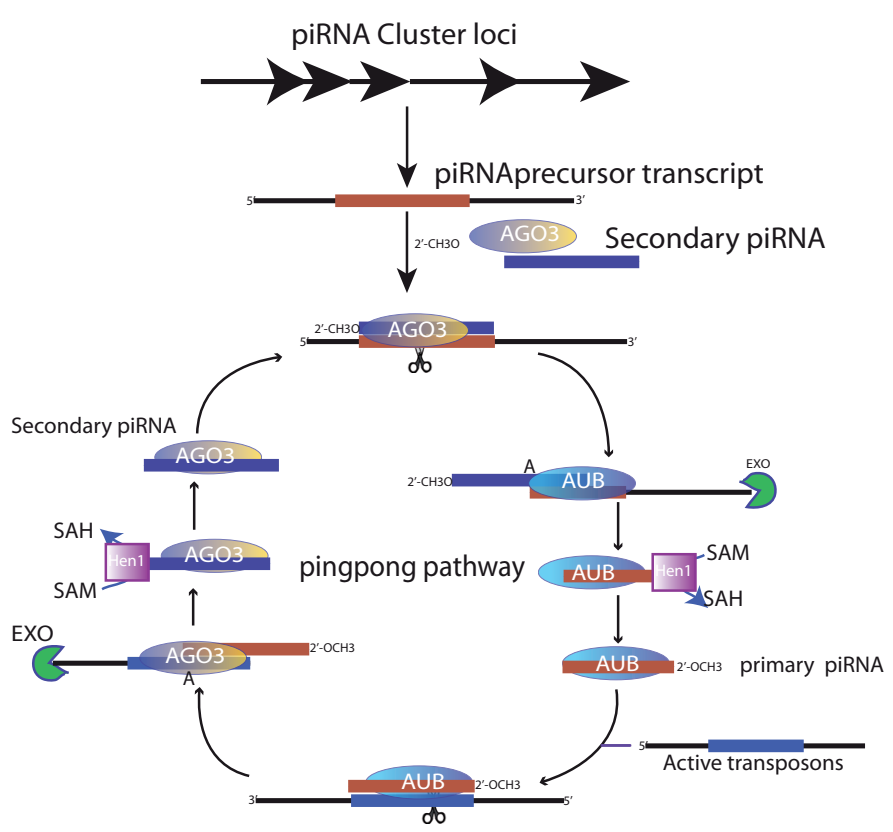

Ping-pong Pathway

Germ line stem cells
B

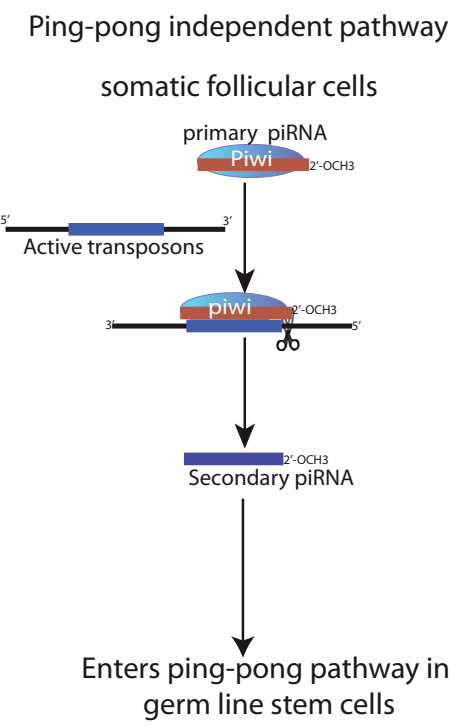

C
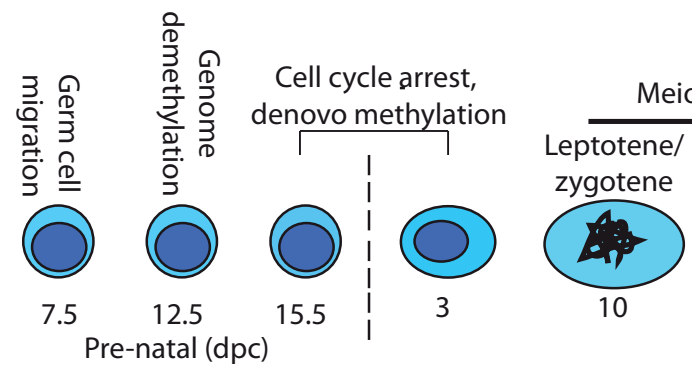

Meiosis

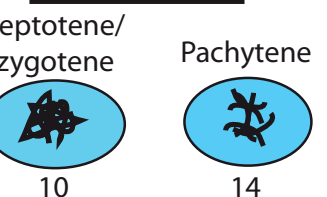

Round spermatid

Elongated
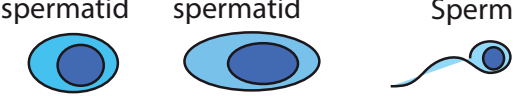

20

27

30

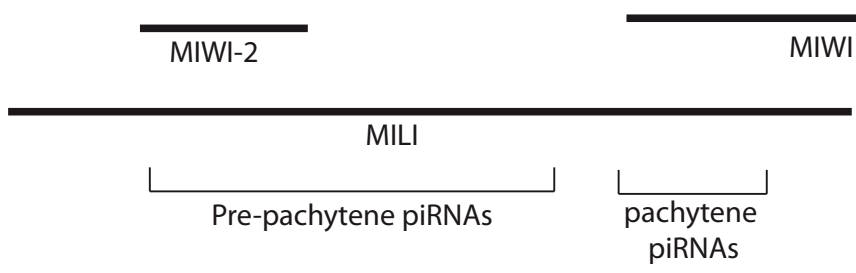

Fig. 2. Piwi RNA biogenesis and expression. (A) Piwi RNA biogenesis in Drosophila. Piwi RNAs (piRNAs) are small RNA molecules 24-32 nt in length that mostly map to transposable elements. Long primary RNA precursors are transcribed from intergenic repetitive elements localized to centromeric regions. Primary RNA precursors are antisense to transposable elements and are processed by Ago 3 bound to sense piRNAs to generate antisense primary piRNAs. Antisense primary piRNAs interact with Aubergine (Aub) and the methyltransferase Hen 1, which methylates the 3' end as a protective measure against exonucleases. Aub bound antisense piRNAs bind active transposons in the cell and process them to generate secondary sense piRNAs. Three-prime ( $\left.3^{\prime}\right)$ ends of secondary sense piRNAs are methylated in the same way as antisense primary piRNAs. The secondary sense piRNAs interact with Ago3 to process the long antisense RNA precursors and generate antisense piRNAs, resulting in the ping-pong mode of piRNA amplification. In Drosophila, the ping-pong mode of piRNA amplification is largely restricted to germ line stem cells. (B) The ping-pong independent pathway is mediated by antisense piRNAs bound to Piwi protein; this complex processes sense transposons to generate secondary sense piRNAs, which participate in pingpong mediated biogenesis of piRNAs. The ping-pong independent pathway is restricted to somatic follicular cells in Drosophila ovaries. ${ }^{*}$ Figure $2 A$ and Figure 2B are adapted from Li et al., 2009. (C) The expression of mouse PIWI proteins MILI, MIWI-2 and MIWI, pre-pachytene piRNAs and pachytene piRNAs during mouse spermatogenesis. Mili expression is seen from day $12.5 \mathrm{dpc}$, when cells are classified as mitotically arrested prenatal germline stem cells, until the formation of round spermatids at day $20 \mathrm{dpp}$. Miwi-2 is expressed from day 15.5 dpc to day 3 dpp, where cells are classified as mitotically arrested prenatal germ line stem cells. Miwi expression is seen from day 14 dpp, where cells are classified as meiotic spermatocytes, until the formation of elongated spermatids. Pre-pachytene piRNAs enriched for sequences that map to transposable elements are expressed from day 15.5 $d p c$ to day 14 dpp of meiosis. Pachytene piRNAs that map to unique regions of the genome are expressed from the pachytene stage of meiosis until the formation of elongated spermatids at day $27 \mathrm{dpp} .{ }^{*}$ Figure $2 \mathrm{C}$ is adapted from Thomson and Lin 2009. 
and map to transposable elements. These piRNAs participate in the ping-pong model and are primarily associated with MILI and MIWI2, where antisense strands bind to MILI and sense strands bind to MIWI-2 (Aravin et al., 2008; Thomson and Lin 2009). The second class of mouse piRNAs is expressed during the meiotic-1 pachytene stage of spermatogenesis and cluster to uniquely mapped noncoding regions of the mouse genome. These piRNAs are referred to as pachytene piRNAs and represent the most abundant class of piRNAs in male germ line tissues. Pachytene piRNAs associate with the MIWI protein and are mostly derived from a single strand of genomic DNA. The role of pachytene piRNAs in meiosis is not clear, but it was shown that the MIWI protein associates with polysomes and binds to several mRNAs through the cap binding complex. This suggests that pachytene piRNAs are capable of silencing the mRNA transcripts they target (Grivna et al., 2006; Aravin et al., 2006). In contrast, pre-pachytene piRNAs might be involved in transposon silencing given the fact that mili deficient mice show an increase in transposon activity (Aravin et al., 2007).

In addition to mammals and Drosophila, the piRNA pathway is well studied in Zebrafish. Piwi proteins in zebrafish are essential for spermatogenesis and associate with small RNAs that are derived mostly from transposable elements (Thomson and Lin 2009). Recent studies have identified piRNA pathways in basal metazoans including Nematostella and Porifera, indicating that piRNA pathways were present in the earliest stages of metazoan evolution. Basal metazoan piRNAs are most similar to pachytene piRNAs and are derived from one strand of DNA. Nonetheless, a few piRNAs are derived from transposable elements, indicating a potential role in transposon silencing (Grimson et al., 2008). In summary, metazoan piRNAs can be broadly divided into two groups: 1) pre-pachytene like piRNAs, which may play an essential role in maintaining genome stability by suppressing transposons, and 2) pachytene piRNA-like piRNAs, whose specific expression at the pachytene stage of meiosis indicates a potential role in meiotic recombination.

\section{Planarian Piwi proteins}

Most studies that examine piRNA and Piwi protein expression in model organisms show that piRNA pathways are primarily expressed in germ line tissues and involved in spematogenesis and oogenesis. Planarian studies have identified three major Piwi proteins: SMEDWI-1, 2 and -3 in Schmidtea mediterranea (Reddien et al., 2004; Palakodeti et al., 2008) and DJPIWI A, B and C in Dugesia Japonica (Rossi et al., 2007). Whole mount in-situ hybridizations showed that all planarian Piwi's are expressed in neoblast cell populations and RNAi experiments revealed that SMEDWI-2 and -3 are essential for neoblast function. Although smedwi-1 is expressed in proliferating neoblasts, knockdown of this gene does not effect the neoblast population, suggesting that smedwi-1 is dispensable for planarian regeneration. Extensive computational analysis of the Schmidtea mediterranea genome identified several smedwi-2 homologs, which are $95-98 \%$ identical to the smedwi-2 gene. Transcript analysis showed that a few of the smedwi-2homologs are expressed in Schmidtea mediterranea (Reddien et al., 2004; Palakodeti et al., 2008), raising the possibility that some smedwi-2 homologs may function as pseudo genes with regulatory roles. Phylogenetic analysis of SMEDWI proteins showed that SMEDWI-3 is most similar to human HIWI (34\% identity and 54\% similarity) and Drosophila AGO3 (32\% identity and $51 \%$ similarity), whereas SMEDWI-1 and 2 form a separate phylogenetic group and show weak homology with PIWI proteins in other species (Palakodeti et al., 2008). Additional studies are needed to determine the sub-cellular localization patterns of different SMEDWI proteins as a first step toward understanding the regulatory roles of each protein in the neoblast cell population.

\section{Planarian piRNAs}

Deep sequencing of small RNA libraries from Schmidtea mediterranea identified a new class of small RNAs that range from 31-33nt in size. Computational analysis showed that 20$30 \%$ of these small RNA molecules map to transposable elements. Knockdown of smedwi's followed by Northern blots using probes against 31-33nt small RNAs revealed that these small RNAs are regulated by SMEDWI-2 and-3, but not SMEDWI-1 (Palakodeti et al., 2008). These findings are supported by the fact that smedwi-2 and -3 RNAi show regeneration defects while smedwi-1 RNAi does not. These results indicate that 31-33nt small RNA species could be piRNAs, but pull down studies using SMEDWI-2 and -3 specific antibodies are needed to confirm this hypothesis. Another clue that these sequences represent authentic piRNAs stems from the observation that small RNAs that map to transposable elements follow the ping-pong model of biogenesis, with the sense strand encoding an ' $A$ ' residue at the 10nt position from the 5' end and the antisense strand showing a strong ' $U$ ' preference at the 5' end. Intriguingly, unlike Drosophila, planarian piRNAs that map to transposable elements are not enriched in specific regions and lack detectable master loci. As with mammals, planarian piRNAs that map uniquely to the planarian genome show a similar distribution to pachytene piRNAs and are highly abundant compared to the piRNAs that map to the transposable elements. These piRNAs might have similar functional roles and it will be interesting to identify the targets that are regulated by these small RNA molecules (Palakdoeti et al., 2008; Friedländer et al., 2009). The fact that planarian and other basal metazoan piRNAs are abundant in adult stem cells, unlike mammalian piRNAs, indicates that piRNA pathways may have initially evolved in adult stem cells and subsequently localized to germ line tissues as complex metazoans evolved. It is worth noting that planarian neoblasts are essential for regeneration and homeostasis, indicating that tight regulation of neoblast function and maintenance of genome integrity are key factors in planarian survival, for which piRNAs and piwi proteins may play a crucial role. Piwi proteins are essential for regeneration and stem cell function in planarians, however the direct interaction of different Piwi proteins with piRNAs has not been established. Moreover, it is not clear if there are targets that are regulated by piRNAs that map to non-coding regions of the genome. Additional studies on piRNA cellular localization for ping-pong dependent and independent pathways are needed to clarify the functional roles of piRNA pathways in planarian neoblasts.

\section{Conclusions and future prospects}

Small RNA-mediated post-transcriptional regulation has emerged as an important regulatory mechanism of gene expression in various cellular processes. Small RNAs have been identified 
in several metozoan species and functional analysis of certain subclasses of small RNAs indicates that these sequences are evolutionarily conserved.

The presence of RNP granules (chromatoid bodies) in the adult neoblast population emphasizes the importance of small RNA mediated regulation of stem cell function in planarians. Two different classe of small RNAs (miRNAs and piRNAs) were recently identified in planarian neoblasts and knockdowns of miRNA and piRNA pathway genes established roles for small RNAs in regeneration and stem cell function. Compared to other small RNA pathways, the piRNA pathway is poorly understood because of its primary expression in germ line tissues. In this regard, planarians provide a useful tool for studying the biogenesis and function of piRNAs, because of their expression in neoblasts, which constitutes 30\% of the total cell population. Studies have also established a role for small RNA pathways in epigenetic modulation of the genome, but a role for planarian small RNAs in, for example, de-novo methylation during planarian regeneration, has yet to be established.

Future experiments in planarian small RNA research will rely on next generation sequencing to identify small RNA molecules that are expressed during different stages of regeneration and in different cells and tissue types. The next major goal of this research is to identify the targets of small RNAs, in hopes of identifying small RNA-mediated regulatory networks that control stem cell function and regeneration. In addition, expression profiles for non-coding RNA molecules such as small nucleolar RNAs (snoRNAs) and long non-coding RNAs (IncRNAs) should be analyzed; these RNA species have been shown to regulate developmental pathways in mammalian species and may play similar roles in planarians.

\section{Acknowledgements}

The authors wish to acknowledge Dr. Brenton R. Graveley, Dr. Yashoda Ghanekar, Dr. Sai Sudha and members of the Palakodeti lab for helpful comments on the manuscript. Work in the Palakodeti lab is supported by the Wellcome/DBT intermediate fellowship awarded by Wellcome trust/ DBT India.

\section{References}

ADELL T, CEBRIÀ F, SALÓ E (2010). Gradients in planarian regeneration and homeostasis. Cold Spring Harb Perspect Biol 2: a000505.

ARAVIN A, GAIDATZIS D, PFEFFER S, LAGOS-QUINTANA M, LANDGRAF P, IOVINO N, MORRIS P, BROWNSTEIN MJ, KURAMOCHI-MIYAGAWA S, NAKANO T, CHIEN M, RUSSO JJ, JU J, SHERIDAN R, SANDER C, ZAVOLAN M, TUSCHL T (2006). A novel class of small RNAs bind to MILI protein in mouse testes. Nature 442: 203-207.

ARAVIN AA, LAGOS-QUINTANA M, YALCIN A, ZAVOLAN M, MARKS D, SNYDER B, GAASTERLAND T, MEYER J, TUSCHL T (2003). The small RNA profile during Drosophila Melanogaster development. Dev Cell 5: 337-350.

ARAVIN AA, SACHIDANANDAM R, BOURC'HIS D, SCHAEFER C, PEZIC D, TOTH KF, BESTOR T, HANNON GJ (2008). A piRNA pathway primed by individual transposons is linked to de novo DNA methylation in mice. Mol Cell 31: 785-799.

ARAVIN AA, SACHIDANANDAM R, GIRARD A, FEJES-TOTH K, HANNON GJ (2007). Developmentally regulated piRNA clusters implicate MILI in transposon control. Science 316: 744-747.

BAEK D, VILLÉN J, SHIN C, CAMARGO FD, GYGI SP, BARTEL DP (2008). The impact of microRNAs on protein output. Nature 455: 64-71.

BARTEL DP (2004).MicroRNAs: genomics, biogenesis, mechanism, and function. Cell 116: 281-297.

BORCHERT GM, LANIER W, DAVIDSON BL (2006). RNA polymerase III transcribes human microRNAs. Nat Struct Mol Biol 13: 1097-1101.

BRENNECKE J, ARAVIN AA, STARK A, DUS M, KELLIS M, SACHIDANANDAM R,
HANNON GJ (2007). Discrete small RNA-generating loci as master regulators of transposon activity in Drosophila. Cell 128: 1089-1103.

FERNANDÉZ-TABOADA E, MORITZ S, ZEUSCHNER D, STEHLING M, SCHÖLER HR, SALÓ E, GENTILE L (2010). Smed-SmB, a member of the LSm protein superfamily, is essential for chromatoid body organization and planarian stem cell proliferation. Development 137: 1055-1065.

FRIEDLÄNDER MR, ADAMIDI C, HAN T, LEBEDEVA S, ISENBARGER TA, HIRST M, MARRA M, NUSBAUM C, LEE WL, JENKIN JC, SÁNCHEZ ALVARADO A, KIM JK, RAJEWSKYN (2009). High-resolution profiling and discovery of planarian small RNAs. Proc Natl Acad Sci USA 106: 11546-11551.

GONZÁLEZ-ESTÉVEZC, ARSENIV, THAMBYRAJAHRS, FELIXDA, ABOOBAKER AA (2009). Diverse miRNA spatial expression patterns suggest important roles in homeostasis and regeneration in planarians. Int J Dev Biol 53: 493-505.

GRIMSON A, SRIVASTAVA M, FAHEY B, WOODCROFT BJ, CHIANG HR, KING N DEGNAN BM, ROKHSAR DS, BARTEL DP (2008). Early origins and evolution of microRNAs and Piwi-interacting RNAs in animals. Nature 455: 1193-1197.

GRIVNA ST, PYHTILAB, LIN H (2006). MIWI associates with translational machinery and PIWl-interacting RNAs (piRNAs) in regulating spermatogenesis. Proc Natl Acad Sci USA 103: 13415-13420.

GURLEY KA, RINK JC, SÁNCHEZ ALVARADO A (2008). Beta-catenin defines head versus tail identity during planarian regeneration and homeostasis. Science 319: 323-327.

HANDBERG-THORSAGER M, FERNANDEZ E, SALO E (2008). Stem cells and regeneration in planarians. Front Biosci 13: 6374-6394.

HANINA SA, MIFSUD W, DOWN TA, HAYASHI K, O'CARROLL D, LAO K, MISKA EA, SURANI MA (2010). Genome-wide identification of targets and function of individual MicroRNAs in mouse embryonic stem cells. PLoS Genet 6:e1001163.

HUANG J, HAO P, CHEN H, HU W, YAN Q, LIU F, HAN ZG (2009). Genome-wide identification of Schistosoma japonicum microRNAs using a deep-sequencing approach. PLoS One 4:e8206.

HUTVAGNER G, SIMARD MJ (2008). Argonaute proteins: key players in RNA silencing. Nat Rev Mol Cell Biol 9: 22-32.

KANELLOPOULOU C, MULJOSA, KUNGAL, GANESANS, DRAPKIN R, JENUWEIN T, LIVINGSTON DM, RAJEWSKY K (2005). Dicer-deficient mouse embryonic stem cells are defective in differentiation and centromeric silencing. Genes Dev 19: 489-501.

KOTAJA N, SASSONE-CORSI P (2007).The chromatoid body: a germ-cell-specific RNA-processing centre. Nat Rev Mol Cell Biol 8: 85-90.

LEE Y, KIM M, HAN J, YEOM KH, LEE S, BAEK SH, KIM VN (2004).MicroRNA genes are transcribed by RNA polymerase II. EMBO $J$ 23: 4051-4060.

LI C, VAGIN VV, LEE S, XU J, MA S, XI H, SEITZ H, HORWICH MD, SYRZYCKA M, HONDABM, KITTLEREL, ZAPPML, KLATTENHOFFC, SCHULZN, THEURKAUF WE, WENG Z, ZAMORE PD (2009). Collapse of germline piRNAs in the absence of Argonaute3 reveals somatic piRNAs in flies. Cell 137: 509-521.

LI YQ, ZENG A, HAN XS, WANG C, LI G, ZHANG ZC, WANG JY, QIN YW, JING Q (2011). Argonaute-2 regulates the proliferation of adult stem cells in planarian. Cell Res. 21:1750-1754.

LIU Q, PAROO Z (2010). Biochemical principles of small RNA pathways. Annu Rev Biochem 79: 295-319.

LU YC, SMIELEWSKA M, PALAKODETI D, LOVCI MT, AIGNER S, YEO GW, GRAVELEY BR (2009). Deep sequencing identifies new and regulated microRNAs in Schmidtea mediterranea. RNA 15: 1483-1491.

M TOMÉ, P LÓPEZ-ROMERO, C ALBO, J C SEPÚLVEDA, B FERNÁNDEZGUTIÉRREZ, A DOPAZO, A BERNAD AND M A GONZÁLEZ (2011). miR-335 orchestrates cell proliferation, migration and differentiation in human mesenchymal stem cells. Cell Death Differ 18: 985-995

MALONE CD, BRENNECKE J, DUS M, STARK A, MCCOMBIE WR, SACHIDANANDAM R, HANNON GJ (2009). Specialized piRNA pathways act in germline and somatic tissues of the Drosophila ovary. Cell 137: 522-535.

NEWMARK PA, SÁNCHEZ ALVARADO A (2002). Not your father's planarian: a classic model enters the era of functional genomics. Nat Rev Genet 3: 210-219.

PALAKODETI D, SMIELEWSKA M, GRAVELEY BR (2006). MicroRNAs from the Planarian Schmidtea mediterranea: a model system for stem cell biology. RNA 12: 1640-1649.

PALAKODETI D, SMIELEWSKA M, LU YC, YEO GW, GRAVELEY BR (2008). The 


\section{A.M. Resch and D. Palakodeti}

PIWI proteins SMEDWI-2 and SMEDWI-3 are required for stem cell function and piRNA expression in planarians. RNA 14: 1174-1186

PASCOLINI R, TEI S, VAGNETTI D, BONDI C (1984). Epidermal cell migration during wound healing in Dugesia lugubris. Observations based on scanning electron microscopy and treatment with cytochalasin. Cell Tissue Res 236: 345-349.

PEARSON BJ, SÁNCHEZ ALVARADO A (2009). Regeneration, stem cells, and the evolution of tumor suppression. Cold Spring Harb Symp Quant Biol 73: 565-572 Review.

PEARSON BJ, SÁNCHEZ ALVARADO A (2010). A planarian p53 homolog regulates proliferation and self-renewal in adult stem cell lineages. Development. 213-221.

PETERSEN CP, REDDIEN PW (2009). Wnt signaling and the polarity of the primary body axis. Cell 139: 1056-1068.

REDDIEN PW, BERMANGE AL, KICZA AM, SÁNCHEZ ALVARADO A (2007). BMP signaling regulates the dorsal planarian midline and is needed for asymmetric regeneration. Development 134: 4043-4051.

RINK JC, GURLEY KA, ELLIOTT SA, SÁNCHEZ ALVARADO A (2009). Planarian Hh signaling regulates regeneration polarity and links Hh pathway evolution to cilia. Science 326: 1406-1410.

ROSSI L, SALVETTI A, MARINCOLA FM, LENAA, DERI P, MANNINI L, BATISTON R, WANG E, GREMIGNI V (2007). Deciphering the molecular machinery of stem cells: a look at the neoblast gene expression profile. Genome Biol 8:R62.

ROUHANA L, SHIBATA N, NISHIMURA O, AGATA K (2010). Different requirements for conserved post-transcriptional regulators in planarian regeneration and stem cell maintenance. Dev Biol 341: 429-443.

SELBACH M, SCHWANHÄUSSER B, THIERFELDER N, FANG Z, KHANIN R, RAJEWSKY N (2008). Widespread changes in protein synthesis induced by microRNAs. Nature 455: 58-63.

SIMÕESMC, LEEJ, DJIKENGA, CERQUEIRAGC, ZERLOTINIA, DASILVA-PEREIRA RA, DALBY AR, LOVERDE P, EL-SAYED NM, OLIVEIRA G (2011). Identification of Schistosoma mansoni microRNAs. BMC Genomics 12: 47
SOLANAJ, LASKO P, ROMERO R (2009). Spoltud-1 is a chromatoid body component required for planarian long-term stem cell self-renewal. Dev Biol 328: 410-421.

SUBRAMANYAM D, LAMOUILLE S, JUDSON RL, LIU JY, BUCAY N, DERYNCK R, BLELLOCH R (2011). Multiple targets of miR-302 and miR-372 promote reprogramming of human fibroblasts to induced pluripotent stem cells. Nat Biotechnol 29: 443-448.

THATCHER EJ, PATTON JG (2010). Small RNAs have a big impact on regeneration. RNA Biol 7: 333-338.

THOMSONT, LIN H (2009). The biogenesis and function of PIWI proteins and piRNAs: progress and prospect. Annu Rev Cell Dev Biol 25: 355-376.

VAGIN VV, SIGOVAA, LI C, SEITZ H, GVOZDEV V, ZAMORE PD (2006). A distinct small RNA pathway silences selfish genetic elements in the germline. Science 313: 320-324.

VISWANATHAN SR, DALEY GQ, GREGORY RI (2008). Selective blockade of microRNA processing by Lin28. Science 320: 97-100.

WAGNER DE, WANG IE, REDDIEN PW (2011). Clonogenic neoblasts are pluripotent adult stem cells that underlie planarian regeneration. Science 332: 811-816.

WANG Y, MEDVID R, MELTON C, JAENISCH R, BLELLOCH R (2007). DGCR8 is essential for microRNA biogenesis and silencing of embryonic stem cell selfrenewal. Nat Genet 39: 380-385.

WANG Y, ZAYAS RM, GUO T, NEWMARK PA (2007). nanos function is essential for development and regeneration of planarian germ cells. Proc Natl Acad Sci USA 104: 5901-5906.

YI R, FUCHS E (2011). MicroRNAs and their roles in mammalian stem cells. J Cell Sci 124: 1775-1783

YOSHIDA-KASHIKAWA M, SHIBATA N, TAKECHI K, AGATA K (2007). DjCBC-1, a conserved DEAD box RNA helicase of the RCK/p54/Me31B family, is a component of RNA-protein complexes in planarian stem cells and neurons. Dev Dyn 236: 3436-3450. 


\section{Further Related Reading, published previously in the Int. J. Dev. Biol.}

An insulin-like peptide regulates size and adult stem cells in planarians.

Miller CM, Newmark PA.

Int J Dev Biol. (2012) 56: 75-82 (doi: 10.1387/ijdb.113443cm)

Planarian regeneration: achievements and future directions after 20 years of research

Emili Saló, Josep F. Abril, Teresa Adell, Francesc Cebriá, Kay Eckelt, Enrique Fernández-Taboada, Mette Handberg-Thorsager, Marta Iglesias, M Dolores Molina and Gustavo Rodríguez-Esteban

Int. J. Dev. Biol. (2009) 53: 1317-1327.

Diverse miRNA spatial expression patterns suggest important roles in homeostasis and regeneration in planarians.

González-Estévez C, Arseni V, Thambyrajah RS, Felix DA, Aboobaker AA.

Int J Dev Biol. (2009) 53:493-505.

Expression of a retinal homeobox $(\mathbf{R x})$ gene during planarian regeneration Linda Mannini, Paolo Deri, Jacopo Picchi and Renata Batistoni

Int. J. Dev. Biol. (2008) 52: 1113-1117

From Planarians to Mammals - the many faces of regeneration

Jerzy Moraczewski, Karolina Archacka, Edyta Brzoska, Maria-Anna Ciemerych, Iwona Grabowska, Katarzyna Janczyk-llach, Wladyslawa Streminska and Malgorzata Zimowska Int. J. Dev. Biol. (2008) 52: 219-227

Expression of DjXnp, a novel member of the SNF2-like ATP-dependent chromatin remodelling genes, in intact and regenerating planarians

Leonardo Rossi, Paolo Deri, Ilaria Andreoli, Vittorio Gremigni, Alessandra Salvetti and Renata Batistoni

Int. J. Dev. Biol. (2003) 47: 293-298

Effects of activators and antagonists of the neuropeptides substance $P$ and substance $\mathrm{K}$ on cell proliferation in planarians

J Baguñà, E Saló and R Romero

Int. J. Dev. Biol. (1989) 33: 261-266.

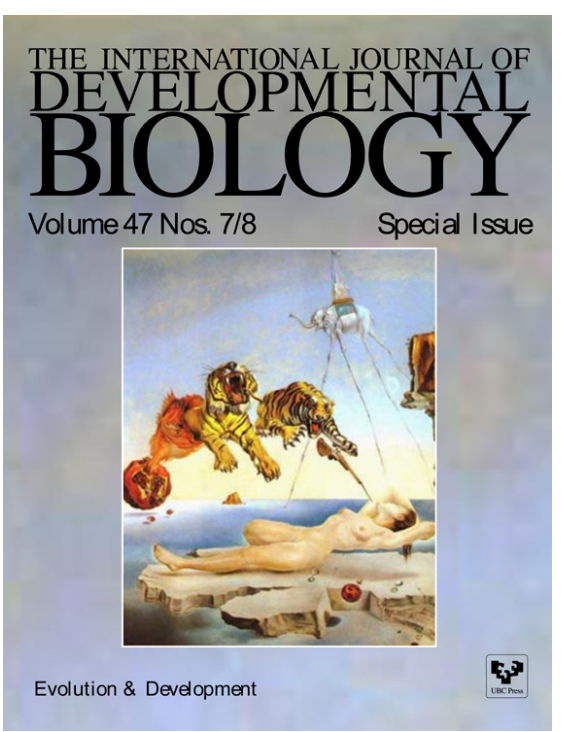

5 yr ISI Impact Factor $(2010)=2.961$
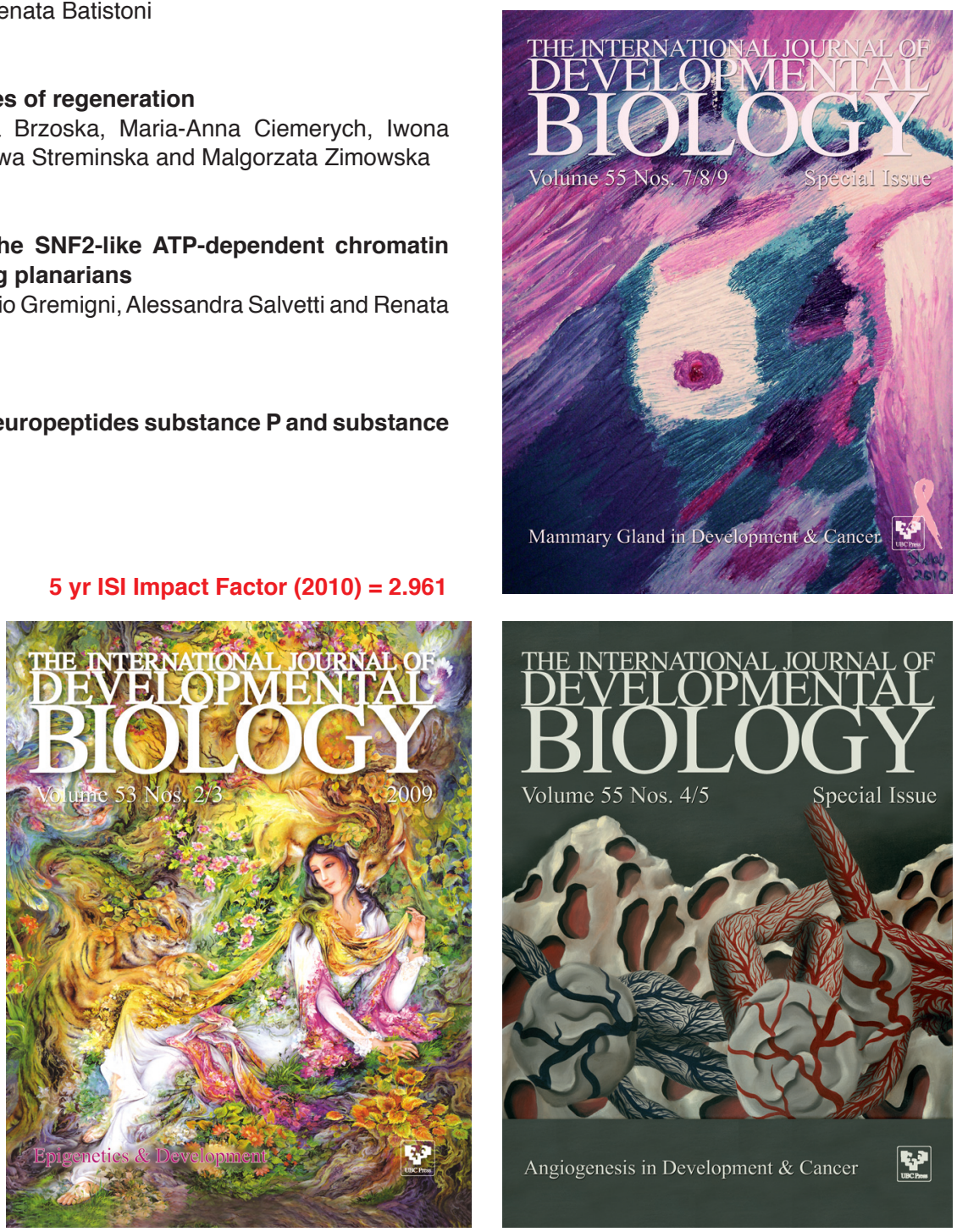